\title{
DNA Methylation as Surrogate Marker For Gastric Cancer
}

\author{
Jung-Hwan $\mathrm{Oh}^{1}$, Sung-Hoon Jung ${ }^{1}$, Seung-Jin Hong ${ }^{2}$, Mun-Gan Rhyu ${ }^{2}$ \\ Departments of ${ }^{1}$ Internal Medicine and ${ }^{2}$ Microbiology, College of Medicine, The Catholic University of Korea, Seoul, Korea
}

\begin{abstract}
Stomach cancer remains, stubbornly, highly prevalent in East Asia. Still, stomach cancer has few biomarkers by which it can be predicted. Helicobacter pylori infection, a known carcinogen of stomach cancer, usually goes undetected prior to cancer diagnosis, due to the poor mucosal environments that its related gastric atrophy causes. We propose, herein, an endoscopic-biopsy-based cancer-predicting DNA methylation marker. We semi-quantitatively examined the methylation-variable sites near the CpG-island margins by radioisotope-labeling methylation-specific polymerase chain reaction in association with $\mathrm{H}$. pylori, which increases age-related over-methylation in $\mathrm{CpG}$ islands of gastric mucosa. These age-related methylation patterns of the transitional- $\mathrm{CpG}$ sites are proposed as useful surrogate markers for stomach cancer. It would be helpful for setting the optimal screening interval for high-risk subjects as well as for estimating the prognosis and the predictability for recurrence of early gastric cancer in patients having undergone endoscopic submucosal dissection. New screening-interval guidelines for gastric cancer should be suggested considering individual risk based on age, severity of atrophy, H. pylori status, and DNA methylation pattern.
\end{abstract}

(J Cancer Prev 2015;20:172-178)

Key Words: Biological markers, CpG Islands, DNA methylation, Helicobacter pylori, Stomach neoplasms

\section{INTRODUCTION}

Gastric cancer was the fifth most common malignancy and the third most common cause of cancer-related deaths worldwide in 2012. ${ }^{1}$ In East Asia, it is the most prevalent cancer. ${ }^{2}$ Both Japan and Korea, uniquely in the world, routinely screen for gastric cancer. The Japanese screening program recommends an uppergastrointestinal series using barium. ${ }^{3}$ The National Health Insurance Corperation of Korea, meanwhile, provides, for detection of early gastric cancer, biannual endoscopy for all adults over the age of 40 years. Early detection of cancer, which can be achieved by identification of high-risk individuals, is essential to the reduction of morbidity and mortality rates. In this effort, endoscopy plays a leading role. One recent gastric cancer study reported a higher mortality reduction rate for the endoscopic screening group relative to a radiographic screening group. ${ }^{4}$
However, no system of risk stratification assessment based on recommended screening intervals has yet been established. ${ }^{5}$

Even though a number of risk factors such as Helicobacter pylori infection, salt intake, smoking, alcohol, family history, atrophic gastritis (AG), and intestinal metaplasia (IM) are well known, they cannot account for all gastric cancers, since gastric carcinogenesis is a multifactorial process. Indeed, a very wide range of factors (genetic, epigenetic, and environmental) can contribute to gastric cancer carcinogenesis. The research into the epigenetic mechanisms of gastric cancer, in any case, has begun to make a mark. The aim of this review is to discuss DNA methylation changes according to $H$. pylori infection, especially focusing on the transitional-CpG site. Such changes in the transitional-CpG sites doubtless will become useful markers for detection of subjects at high risk of gastric cancer.

Received August 24, 2015, Revised September 7, 2015, Accepted September 8, 2015

Correspondence to: Mun-Gan Rhyu

Department of Microbiology, College of Medicine, The Catholic University of Korea, 222 Banpo-daero, Seocho-gu, Seoul 06591, Korea

Tel: +82-2-2258-7344, Fax: +82-2-596-8969, E-mail: rhyumung@catholic.ac.kr, ORCID: Mun-Gan Rhyu, http://orcid.org/0000-0002-4828-7915

Copyright (c) 2015 Korean Society of Cancer Prevention

(c) This is an Open Access article distributed under the terms of the Creative Commons Attribution Non-Commercial License (http://creativecommons.org/licenses/by-nc/4.0) which permits unrestricted non-commercial use, distribution, and reproduction in any medium, provided the original work is properly cited. 


\section{ENDOSCOPIC SCREENING}

\section{Atrophy/intestinal metaplasia}

AG and the development of IM are considered to be the primary premalignant conditions leading to gastric cancer onset. However, the association of atrophy with gastric cancer and the link between its progression and gastric cancer development, in longitudinal cohort studies, have been tenuous. The rate of progression of AG to gastric cancer fluctuates from $0 \%$ to $10 \%$ with an annual person-per-year incidence lower than $1 \%{ }^{6}$ The annual incidences of gastric cancer within five years of diagnosis were reported as $0.1 \%$ for patients with AG, $0.25 \%$ for IM, $0.6 \%$ for mild-to-moderate dysplasia, and $6 \%$ for severe dysplasia. ${ }^{7}$

For more rational classification of gastritis, the updated Sydney system was developed. ${ }^{8}$ And to investigate the association between gastritis and gastric cancer risk, an international group of gastroenterologists and pathologists (the Operative Link for Gastritis Assessment [OLGA]) has suggested the OLGA staging system, which arranges the histological phenotypes of gastritis on a scale of gastric cancer risk progressively increasing from lowest (OLGA stage 0 ) to highest (OLGA stage IV). ${ }^{9}$ Both systems, however, require five endoscopically obtained stomach biopsies for clarification of the distribution of atrophic change. This, unfortunately, renders problematic their application to all gastritis patients in actual clinical settings.

Correa proposed the precancerous cascade, which describes the process of active chronic inflammation's initiation of the development of gastric cancer from AG, IM, and dysplasia. ${ }^{10}$ Fully one-third of gastric cancer patients in two studies, however, showed no precancerous lesions in the gastric mucosa. ${ }^{11,12}$ Their cancers, moreover, were detected without signs of mucosal atrophy. Indeed, IM carries a low risk of progression to cancer, and such lesions are commonly found in everyday practice. Thus, surveillance programs based on the detection of precancerous lesions are of questionable utility. To overcome these problems, research into and implementation of promising biomarkers for early detection of gastric cancer should be vigorously pursued.

\section{Helicobacter pylori}

H. pylori is a known carcinogen that can form a developmental link between AG, IM, or dysplasia. It is related to both diffusetype and intestinal-type cancer. H. pylori infection usually is acquired during childhood and persists for years, though it tends to disappear once AG and IM extend, which produces an unfavorable environment for its colonization. ${ }^{13}$ It has been suggested that in order to prevent gastric cancer onset in Korea, $H$. pylori should be eradicated before IM has a chance to develop. ${ }^{14}$ According to a community-based study in Taiwan, mass eradication of $H$. pylori infection led to a substantial reduction in the incidence of AG; however, it did not reduce the incidence of $\mathrm{IM}^{15}$ It seems that the oncogenic potential of $H$. pylori infection persists after the infection itself is gone. ${ }^{16}$ Indeed, whereas not all people infected with $H$. pylori develop gastric cancer (in fact, the majority do not), $H$, pylori-negative patients are among those afflicted with the disease. ${ }^{17}$ The prevalence of $H$. pylori-negative gastric cancer, most of which cases might be expected to have involved previous $H$. pylori infection, reportedly ranges from $0.42 \%$ to $5.4 \%$ of all gastric cancers. ${ }^{18}$ Therefore, $H$. pylori itself cannot be a useful marker for detection of gastric cancer.

\section{SERUM PEPSINOGEN AND HELICOBACTER PYLORI ANTIBODY}

Serum pepsinogen $(\mathrm{PG})$ was introduced as an objective method of atrophic-change detection that can overcome the problem of the interobserver variation in endoscopy-based AG diagnosis. ${ }^{19} \mathrm{~A}$ PG I/II ratio $<3.0$ has been accepted as the cut-off point for severity of AG. However, PG screening, due to its low predictive value, has not been adopted as a screening method. Instead, it has been developed for risk stratification of gastric cancer that entails assessment of two risk factors, namely serum immunoglobulin $\mathrm{G}$ anti- $H$. pylori antibody level and PG level. ${ }^{16}$ To clarify the influence of the interaction of $H$. pylori infection with AG on gastric cancer risk, one study formed the following four subject groups: (1) H. pylori (-)/PG (-) (group A), (2) H. pylori (+)/PG (-) (group B), (3) H. pylori (+)/PG (+) (group C), and (4) H. pylori $(-) / P G(+)$ (group D). It demonstrated that the risk of gastric cancer was higher in group $C$ or group $D$ than in group $A$ or group B. ${ }^{16}$ Notwithstanding the simplicity and non-invasive aspect of this methodology, it effectively raised the issue of the appropriateness of the PG cut-off level and showed that it could consistently distinguish gastric adenoma and gastric cancer. Subsequently, a new, modified $\mathrm{ABCD}$ method using two different PG cutoff values (I/II ratio 3.1 and 4.1) was proposed as a supplemental screening tool for both gastric adenoma and gastric cancer in Korea. ${ }^{20}$

\section{DNA METHYLATION AS NEW BIOMARKER}

\section{Role of DNA methylation}

Epigenetics is a study that includes a number of modifications in the genomic structure that affect gene expression without 
altering the primary DNA sequence. Epigenetic silencing of genes by aberrant DNA methylation is recognized as a crucial component of the mechanism underlying tumorigenesis. ${ }^{21}$ DNA methylation refers to a methyl group's addition to or subtraction from cytosine residue in a sequence of DNA. ${ }^{22}$ DNA methylation occurs almost exclusively at $\mathrm{CpG}$ dinucleotides. DNA methylation has been known to suppress repetitive DNA sequences initially such as retroviruses and retroelements that comprise one-fourth of the human genome. ${ }^{23}$ Most CPG sites in the genome are thus highly methylated, though $\mathrm{CPG}$ islands, which are clusters of adjacent $\mathrm{CpG}$ sites, often are unmethylated. ${ }^{24}$

Studies have demonstrated that both hypermethylation of tumor-suppressor genes and hypomethylation of retroelements are frequently found in gastric cancer. ${ }^{25}$ DNA hypermethylation of tumor-suppressor genes such as CDH1, CDKN2A, MLH1, and $R U N X 3$ was associated with early detection of gastric cancer, ${ }^{26}$ while the methylation levels of retroelements are decreased in precancerous IM and dysplasia lesions as well as cancer lesions. ${ }^{27}$ However, gene-specific hypermethylation and genome-wide hypomethylation are known to be independent events in carcinogenesis. ${ }^{28}$ Obviously, the role of methylation in cancer development remains frustratingly murky.

\section{CpG-island margins vs. CpG-island centers}

There have been several studies on DNA methylation from endoscopy-obtained non-neoplastic gastric mucosa. The methylation level of $C D K N 2 A$ was shown to be both high in patients with IM, and correlated with lower PG 1/11 ratio. ${ }^{29}$ Over-expression of $T P 73$ was suggested as a marker for assessment of high-risk chronic gastritis. ${ }^{30}$ The methylation levels of MOS in non-neo- plastic gastric mucosa were found to be increased in gastric cancer patients. ${ }^{31}$ Meanwhile, in a comparison of in healthy $H$. pyloriinfected subjects with cancer patients, it was determined that most of the CpG-island genes had been similarly methylated, whereas only a few were more frequently methylated in the cancer patients. ${ }^{32-34}$ The genes displaying more frequent methylation in the cancer patients were frequently methylated in the antrum where $H$. pylori infection had initiated AG, but infrequently in the body. ${ }^{32}$ Moreover, those genes' methylation was not associated with mucosal atrophy, IM, or degree of inflammation. Clearly, more precise H. pylori-associated methylation markers are needed for identification of high-risk individuals at early stages of gastric cancer.

We have suggested a new DNA methylation concept. CpGisland regions can be divided into two parts, the center and the margin. Contrary to most studies on DNA methylation focusing on the CpG-island center, we emphasized the CpG-island margin, or in other words the transitional-CpG sites, which are the methylation-variable sites between hypomethylated genes and hypermethylated retroelements (Fig. 1A). ${ }^{35}$ The densely methylated retroelements that are distributed throughout the human genome might initiate the spread of DNA methylation to the adjacent genes in response to down-regulation of adjacent genes. ${ }^{36}$ The retroelements are classified into two groups according to their ability to encode reverse transcriptase for selfreplication: autonomous L1 (a LINE element) and LTR (long terminal repeats) and non-autonomous Alu (a SINE element). Housekeeping genes contain rich $\mathrm{CpG}$ islands in promotor regions, where tissue-specific genes lack $\mathrm{CpG}$ islands. ${ }^{37}$ The CpG-island centers of housekeeping genes are usually resistant to

A

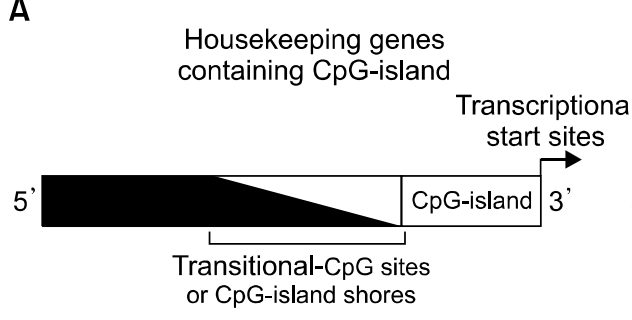

B

CpG density

Methylation-variation range (\%)

Methylation propensity

Helicobacter pylori-associated

methylation

Methylation effect

Methylation change in the

non-cancerous mucosa

of cancer patients
CpG-island margin

High
$0-100$
Variable
Frequent

Phenotype stabilization Decrease methylation in the antrum of closed-type atrophic cases, increased methylation in the body
Stomach-specific genes lacking $\mathrm{CpG}$-island

Transcriptional

start sites

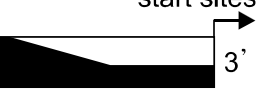

Transitional-CpG sites

CpG-island center

Low

0-40

Resistant

Frequent

Gene inactivation Increased methylation of a few genes in the antrum regardless of gastric atrophy
Figure 1. Methylation-variable $\mathrm{CpG}$ sites around transcriptional start sites. (A) Schematics displaying locations of transitional-CpG sites in housekeeping genes and stomach-specific genes. The transitional-CpG sites are located between the highly methylated retroelements (closed box) and the weakly methylated genes (open box). (B) Comparison of methylation properties between CpG-island margins and CpGisland centers in housekeeping genes containing $\mathrm{CpG}$ islands. 
DNA methylation (Fig. 1B). The methylation effect of CpG-island centers is the inactivation of individual genes. Compared with CpG-island centers, CpG-island margins are variably methylated in a tissue-type-dependent manner. In H. pylori-infected gastric mucosa, they display age-related methylation changes. ${ }^{38}$ The term of CpG island shores, which is similar to the transitional CpG sites, was described in a sense that it was related to the induction of terminal cell differentiation. ${ }^{39}$

We have proposed that the role of methylation might be the stabilization of new stem cell phenotypes rather than gene inactivation. ${ }^{38}$ Chronic $H$. pylori infection induces repopulation of the stomach with bone-marrow-derived cells, which suggests that epithelial cancers can arise from such cells. ${ }^{40,41}$ New fixed stem cells in the $H$. pylori-infected mucosa can be methylated to preserve the re-established transcription profiles. ${ }^{36}$ That is, the methylation of numerous housekeeping genes stabilizes newly established phenotypes of stem cells recruited into the H. pyloriinfected stomach mucosa. The transitional-CpG sites are promptly methylated under the influence of adjacent retroelements, which can lock the re-established transcription profiles of new stem cells. Accordingly, the role of methylation is considered to be the stabilization of new stem cell phenotypes. Therefore, the transitional-CpG sites associated with $H$. pylori infection can be applied as potential markers for gastric stem cells.

\section{Helicobacter pylori, DNA methylation, and gastric cancer}

At the present time, there are no recognized suitable markers of gastric dysplasia or cancer other than atrophy, IM and H. pylori status. $^{42}$ According to the field cancerization theory, DNA methylation changes induced by $H$. pylori infection accumulate in the gastric mucosa before cancer cells are detected by endoscopy, since some new stem cells can possess both cancerrelated methylation patterns and oncogenic mutations prior to the development of gastric cancer. ${ }^{43,44}$ The prevalence of $H$. pylori in early gastric cancer has been found to be higher than that in advanced gastric cancer. ${ }^{45}$ Whereas the histological characteristics of advanced cancer in the elderly typically show severe atrophic changes caused by the presence of long-standing $H$. pylori infection, by the time of cancer detection, the $H$. pylori infection has disappeared. This indicates that $H$. pylori infection potently induces methylation, and that the methylation level decreases to a certain level after active $H$. pylori infection disappears. Specific CpG islands in non-cancerous gastric mucosa might be associated with gastric cancer risk in $H$. pylori-positive individuals who have higher methylation levels than those who are H. pylori-negative. ${ }^{32,46}$ Quantitative methylation levels have been found to be higher in GC patients than in healthy controls, irrespective of $H$. pylori. ${ }^{46}$ They can be associated with gastric cancer in $H$. pylori-negative individuals who had past $H$. pylori infection. ${ }^{47}$

We have conducted several studies on transitional-CpG methylation as an epigenetic marker. ${ }^{35,36,38,48}$ Most studies on DNA methylation of CpG-island centers have used DNA only from the antrum, not from the body of the stomach. However, we demonstrated that the methylation patterns of the transitional-CpG sites differed between the stomach antrum and body (Fig. 1B). ${ }^{38}$ We semi-quantitatively analyzed, by radioisotope-labeling methylation-specific polymerase chain reaction, methylation-variable sites at the CpG-island margins and near the transcriptional start sites of tissue-specific genes lacking CpG islands. Specifically, we selected ten housekeeping genes adjacent to $A l u(C D H 1, A R R D C 4$, PPARG, TRAPPC2L, MLH1, and SHH) or LTR retroelements (MMP2, CDKN2A, RUNX2, and RUNX3) along with nine stomach-specific genes (TFF2, PGC, ATP4B, TFF1, TFF3, GHRL, $P G A, A T P 4 A$, and $A P C$ ). Both the housekeeping genes and stomach-specific genes were rapidly methylated to a high-plateau frequency in the $H$. pylori-positive antrum, while most of the housekeeping genes slowly increased to a peak frequency in the body. High methylation levels of transitional-CpG sites in the body of non-cancerous gastric mucosa have been identified as potential cancer-risk-predicting markers. ${ }^{48}$ The housekeeping genes according to our results tended to be frequently overmethylated in the body mucosa of the patients with gastric cancer compared with those of the H. pylori-positive controls. High-frequency over-methylation was defined as two or more over-methylated genes among the LTR-adjacent genes (MMP2, CDKN2A, RUNX2, and RUNX3) and one or more over-methylated genes in both the Aluradjacent gene group (CDH1, ARRDC4, PPARG, and TRAPPC2L) and the stomach-specific gene group (TFF2, PGC, ATP4B, TFF1, TFF3, GHRL, PGA, and ATP4A). The body, not the antrum, was significantly associated with the risk of gastric cancer with open-type atrophy (OR, 13.4; 95\% confidence interval, 3.8-46.8). Additionally, the OR value in early gastric cancer was much greater than in advanced gastric cancer (OR, 18.8 vs. 8.3) ${ }^{48}$ That is, slowly over-methylated genes were frequent in the body of patients with gastric cancer with open-type atrophy. By contrast, the methylation of Alu-adjacent genes rapidly changed in the antrum, which was hardly increased in the antrum of patients with gastric cancer. ${ }^{48}$ These markers therefore would be helpful for recognizing gastric cancer early, prior to detection of lesions by endoscopy. 


\section{Clinical implications and future directions}

DNA methylation is expected to be a good biomarker in clinical practice. First, it would prove helpful for setting the optimal screening interval for high-risk subjects, which at present remains controversial. A retrospective cohort study in Korea indicated that the optimal interval was 2 years, which finding is consistent with the nationwide gastric cancer screening program. ${ }^{49}$ Another Korean study suggested that whereas endoscopy intervals of 3 years or less showed similar benefits, family members of gastric cancer patients should be screened more frequently than every three years. ${ }^{50}$ Similarly, a European guideline recommended that patients with extensive AG and/or IM undergo an endoscopic check-up every three years. ${ }^{51}$ But subjects showing low-risk results by biomarker would not need to be tested even every two years. This would improve, to a certain extent at least, cost effectiveness. Also, it would facilitate the formulation and adoption of new, other-than-mass-screening strategies for management of high-risk subjects. Secondly, DNA methylation would be helpful for establishing follow-up treatment plans for patients having undergone endoscopic submucosal dissection (an endoscopy-based therapeutic modality for treatment of gastric neoplasms), as it is highly possible that patients with gastric neoplasm will be found to have other synchronous and/or metachronous lesions as well. DNA methylation as a biomarker, again after completion of endoscopic submucosal dissection, would be useful as a means of estimating the prognosis and the predictability for recurrence of early gastric cancer.

It is well accepted that precancerous theory has explained the gastritis-metaplasia-carcinoma sequence. ${ }^{10}$ Meanwhile, 'paracancerous' concept has been suggested, according to which most IMs, known as 'precancerous' lesions, are only 'paracancerous. ${ }^{.52}$ In fact, about one-third of cancer patients have shown no precancerous lesions in the background mucosa of cancer tissues. ${ }^{11,13}$ Thus, the paracancerous theory might complement the precancerous theory. In this light, new screening-interval guidelines for gastric cancer should be suggested considering individual risk based on age, severity of atrophy, H. pylori status, and DNA methylation pattern.

We classified atrophic severity into closed-type AG, in which the atrophic border remains on the lesser curvature of the corpus, and open-type AG, in which the atrophic border extends along the anterior and posterior walls of the stomach. This classification was based on the concept that, because $H$. pylori-induced damage progresses from the antrum into the gastric corpus, an atrophic border can be visualized along the lesser curvature of the corpus followed by the greater curvature. ${ }^{53,54}$ We have already suggested the high-risk methylation pattern in antrum and body. ${ }^{48}$ Further studies on transitional-CpG methylation can accelerate the clinical application of epigenetic markers for $H$. pylori infection and cancer-risk prediction.

\section{CONCLUSIONS}

H. pylori infection promotes the recruitment of bone-marrow stem cells that up-regulate stomach-specific genes for adaptation to the stomach-tissue environment. Methylation-variable sites around CpG islands, also known as transitional-CpG sites, are concurrently methylated in both $H$. pylori-positive subjects and H. pylori-negative subjects with a history of infection. The powerful methylation changes at transitional-CpG sites are likely to provide information on the process of glandular reorganization; as such, they might also be useful biomarkers for detection of high-risk factors related to gastric cancer. Certainly, they suggest powerful new guidelines for screening of high-risk subjects.

\section{ACKNOWLEDGMENTS}

This work was supported by the Catholic Medical Center Research Foundation made in the program year of 2013 (5-2013-B0001-00033; JH Oh, MG Rhyu, SH Jung, and SJ Hong) and (5-2013-B0001-00052; SH Jung, JH Oh, SJ Hong, and MG Rhyu).

\section{CONFLICTS OF INTEREST}

No potential conflicts of interest were disclosed.

\section{REFERENCES}

1. Ferlay J, Soerjomataram I, Dikshit R, Eser S, Mathers C, Rebelo M, et al. Cancer incidence and mortality worldwide: sources, methods and major patterns in GLOBOCAN 2012. Int J Cancer 2015; 136:E359-86.

2. Bray F, Ren JS, Masuyer E, Ferlay J. Global estimates of cancer prevalence for 27 sites in the adult population in 2008. Int J Cancer 2013;132:1133-45.

3. Hamashima C, Shibuya D, Yamazaki H, Inoue K, Fukao A, Saito H, et al. The Japanese guidelines for gastric cancer screening. Jpn J Clin Oncol 2008;38:259-67.

4. Hamashima C, Ogoshi K, Narisawa R, Kishi T, Kato T, Fujita K, et al. Impact of endoscopic screening on mortality reduction from gastric cancer. World J Gastroenterol 2015;21:2460-6.

5. Choi IJ. Endoscopic gastric cancer screening and surveillance in high-risk groups. Clin Endosc 2014:47:497-503. 
6. Vannella L, Lahner E, Osborn J, Bordi C, Miglione M, Delle Fave $\mathrm{G}$, et al. Risk factors for progression to gastric neoplastic lesions in patients with atrophic gastritis. Aliment Pharmacol Ther 2010; 31:1042-50.

7. de Vries AC, van Grieken NC, Looman CW, Casparie MK, de Vries E, Meijer GA, et al. Gastric cancer risk in patients with premalignant gastric lesions: a nationwide cohort study in the Netherlands. Gastroenterology 2008;134:945-52.

8. Dixon MF, Genta RM, Yardley JH, Correa P. Classification and grading of gastritis. The updated Sydney System. International Workshop on the Histopathology of Gastritis, Houston 1994. Am J Surg Pathol 1996:20:1161-81.

9. Rugge M, Meggio A, Pennelli G, Piscioli F, Giacomelli L, De Pretis G, et al. Gastritis staging in clinical practice: the OLGA staging system. Gut 2007:56:631-6.

10. Correa P, Piazuelo MB. The gastric precancerous cascade. J Dig Dis 2012;13:2-9.

11. Yoshida T, Kato J, Inoue I, Yoshimura N, Deguchi H, Mukoubayashi C, et al. Cancer development based on chronic active gastritis and resulting gastric atrophy as assessed by serum levels of pepsinogen and Helicobacter pylori antibody titer. Int J Cancer 2014; 134:1445-57.

12. Agoston AT, Odze RD. Evidence that gastric pit dysplasia-like atypia is a neoplastic precursor lesion. Hum Pathol 2014;45:446-55.

13. Correa P, Piazuelo MB. Helicobacter pylori Infection and Gastric Adenocarcinoma. US Gastroenterol Hepatol Rev 2011;7:59-64

14. Kim N, Park RY, Cho SI, Lim SH, Lee KH, Lee W, et al. Helicobacter pylori infection and development of gastric cancer in Korea: long-term follow-up. J Clin Gastroenterol 2008;42:448-54.

15. Lee YC, Chen TH, Chiu HM, Shun CT, Chiang H, Liu TY, et al. The benefit of mass eradication of Helicobacter pylori infection: a community-based study of gastric cancer prevention. Gut 2013; 62:676-82

16. Ohata H, Kitauchi S, Yoshimura N, Mugitani K, Iwane M, Nakamura $\mathrm{H}$, et al. Progression of chronic atrophic gastritis associated with Helicobacter pylori infection increases risk of gastric cancer. Int J Cancer 2004;109:138-43.

17. Yoon H, Kim N, Lee HS, Shin CM, Park YS, Lee DH, et al. Helicobacter pylori-negative gastric cancer in South Korea: incidence and clinicopathologic characteristics. Helicobacter 2011; $16: 382-8$.

18. Yamamoto $\mathrm{Y}$, Fujisaki J, Omae M, Hirasawa $\mathrm{T}$, Igarashi $\mathrm{M}$. Helicobacter pylori-negative gastric cancer: characteristics and endoscopic findings. Dig Endosc 2015:27:551-61.

19. Park YH, Kim N. Review of atrophic gastritis and intestinal metaplasia as a premalignant lesion of gastric cancer. J Cancer Prev 2015:20:25-40.

20. Park CH, Kim EH, Jung DH, Chung H, Park JC, Shin SK, et al. The new modified $A B C D$ method for gastric neoplasm screening [published online ahead of print February 8, 2015]. Gastric Cancer. doi: 10.1007/s10120-015-0473-4.

21. Ushijima T, Nakajima T, Maekita T. DNA methylation as a marker for the past and future. J Gastroenterol 2006;41:401-7.

22. Selaru FM, David S, Meltzer SJ, Hamilton JP. Epigenetic events in gastrointestinal cancer. Am J Gastroenterol 2009;104:1910-2.

23. Yoder JA, Walsh CP, Bestor TH. Cytosine methylation and the ecology of intragenomic parasites. Trends Genet 1997;13:335-40.

24. Gardiner-Garden M, Frommer M. CPG islands in vertebrate genomes. J Mol Biol 1987;196:261-82.
25. Wang K, Yuen ST, Xu J, Lee SP, Yan HH, Shi ST, et al. Whole-genome sequencing and comprehensive molecular profiling identify new driver mutations in gastric cancer. Nat Genet 2014; 46:573-82.

26. Ushijima T, Sasako M. Focus on gastric cancer. Cancer Cell 2004:5:121-5.

27. Bae JM, Shin SH, Kwon HJ, Park SY, Kook MC, Kim YW, et al. Alu and LINE-1 hypomethylations in multistep gastric carcinogenesis and their prognostic implications. Int J Cancer 2012;131:1323-31.

28. Widschwendter M, Jiang G, Woods C, Müller HM, Fiegl H, Goebel $\mathrm{G}$, et al. DNA hypomethylation and ovarian cancer biology. Cancer Res 2004:64:4472-80.

29. Tahara T, Arisawa T, Shibata T, Wang FY, Nakamura M, Sakata M, et al. Risk prediction of gastric cancer by analysis of aberrant DNA methylation in non-neoplastic gastric epithelium. Digestion 2007:75:54-61.

30. Carrasco G, Diaz J, Valbuena JR, Ibanez P, Rodriguez P, Araya G, et al. Overexpression of p73 as a tissue marker for high-risk gastritis. Clin Cancer Res 2010;16:3253-9.

31. Shin CM, Kim N, Park JH, Kang GH, Kim JS, Jung HC, et al. Prediction of the risk for gastric cancer using candidate methylation markers in the non-neoplastic gastric mucosae. J Pathol 2012;226:654-65.

32. Maekita T, Nakazawa K, Mihara M, Nakajima T, Yanaoka K, Iguchi $\mathrm{M}$, et al. High levels of aberrant DNA methylation in Helicobacter pylori-infected gastric mucosae and its possible association with gastric cancer risk. Clin Cancer Res 2006;12:989-95.

33. Perri F, Cotugno R, Piepoli A, Merla A, Quitadamo M, Gentile A, et al. Aberrant DNA methylation in non-neoplastic gastric mucosa of $\mathrm{H}$. Pylori infected patients and effect of eradication. Am J Gastroenterol 2007;102:1361-71.

34. Kang GH, Lee S, Cho NY, Gandamihardja T, Long TI, Weisenberger DJ, et al. DNA methylation profiles of gastric carcinoma characterized by quantitative DNA methylation analysis. Lab Invest 2008:88:161-70.

35. Kang MI, Rhyu MG, Kim YH, Jung YC, Hong SJ, Cho CS, et al. The length of CpG islands is associated with the distribution of Alu and L1 retroelements. Genomics 2006;87:580-90.

36. Rhyu MG, Oh JH, Hong SJ. Epigenetic implication of gene-adjacent retroelements in Helicobacter pylori-infected adults. Epigenomics 2012:4:527-35.

37. She X, Rohl CA, Castle JC, Kulkarni AV, Johnson JM, Chen R. Definition, conservation and epigenetics of housekeeping and tissue-enriched genes. BMC Genomics 2009; 10:269.

38. Hong SJ, Lee HJ, Oh JH, Jung SH, Min KO, Choi SW, et al. Age-related methylation patterning of housekeeping genes and tissue-specific genes is distinct between the stomach antrum and body. Epigenomics 2013;5:283-99.

39. Doi A, Park IH, Wen B, Murakami P, Aryee MJ, Irizarry R, et al. Differential methylation of tissue- and cancer-specific CpG island shores distinguishes human induced pluripotent stem cells, embryonic stem cells and fibroblasts. Nat Genet 2009;41:1350-3.

40. Houghton J, Stoicov C, Nomura S, Rogers AB, Carlson J, Li H, et al. Gastric cancer originating from bone marrow-derived cells. Science 2004:306:1568-71

41. Varon C, Dubus P, Mazurier F, Asencio C, Chambonnier L, Ferrand J, et al. Helicobacter pylori infection recruits bone marrow-derived cells that participate in gastric preneoplasia in mice. Gastroenterology 2012;142:281-91. 
42. Correa P, Piazuelo MB, Wilson KT. Pathology of gastric intestinal metaplasia: clinical implications. Am J Gastroenterol 2010;105: 493-8.

43. Saikawa Y, Fukuda K, Takahashi T, Nakamura R, Takeuchi H, Kitagawa Y. Gastric carcinogenesis and the cancer stem cell hypothesis. Gastric Cancer 2010;13:11-24.

44. Qu Y, Dang S, Hou P. Gene methylation in gastric cancer. Clin Chim Acta 2013;424:53-65.

45. Kato M, Asaka M, Shimizu Y, Nobuta A, Takeda H, Sugiyama T; Multi-Centre Study Group. Relationship between Helicobacter pylori infection and the prevalence, site and histological type of gastric cancer. Aliment Pharmacol Ther 2004;20 Suppl 1:85-9.

46. Nakajima T, Maekita T, Oda I, Gotoda T, Yamamoto S, Umemura $S$, et al. Higher methylation levels in gastric mucosae significantly correlate with higher risk of gastric cancers. Cancer Epidemiol Biomarkers Prev 2006;15:2317-21.

47. Nanjo S, Asada K, Yamashita S, Nakajima T, Nakazawa K, Maekita $\mathrm{T}$, et al. Identification of gastric cancer risk markers that are informative in individuals with past $\mathrm{H}$. pylori infection. Gastric Cancer 2012;15:382-8.

48. Oh JH, Rhyu MG, Jung SH, Choi SW, Kim SI, Hong SJ. Slow overmethylation of housekeeping genes in the body mucosa is associated with the risk for gastric cancer. Cancer Prev Res (Phila) 2014;7:585-95.

49. Bae JM, Shin SY, Kim EH. Optimal interval for repeated gastric cancer screening in normal-risk healthy korean adults: a retrospective cohort study [published online ahead of print January
30, 2015]. Cancer Res Treat, doi: 10.4143/crt. 2014.098.

50. Nam JH, Choi IJ, Cho SJ, Kim CG, Jun JK, Choi KS, et al. Association of the interval between endoscopies with gastric cancer stage at diagnosis in a region of high prevalence. Cancer 2012;118:4953-60

51. Dinis-Ribeiro M, Areia M, de Vries AC, Marcos-Pinto R, MonteiroSoares M, O'Connor A, et al; MAPS Participants; European Society of Gastrointestinal Endoscopy; European Helicobacter Study Group; European Society of Pathology; Sociedade Portuguesa de Endoscopia Digestiva. Management of precancerous conditions and lesions in the stomach (MAPS): guideline from the European Society of Gastrointestinal Endoscopy (ESGE), European Helicobacter Study Group (EHSG), European Society of Pathology (ESP), and the Sociedade Portuguesa de Endoscopia Digestiva (SPED). Virchows Arch 2012;460:19-46.

52. Meining A, Morgner A, Miehlke S, Bayerdörffer E, Stolte M. Atrophy-metaplasia-dysplasia-carcinoma sequence in the stomach: a reality or merely an hypothesis? Best Pract Res Clin Gastroenterol 2001;15:983-98.

53. Kimura K, Takemoto $\mathrm{T}$. An endoscopic recognition of the atrophic border and its significance in chronic gastritis. Endoscopy 1969; 1:87-97.

54. Ahn SY, Lee SY, Hong SN, Kim JH, Sung IK, Park HS, et al. Endoscopic diagnosis of open-type atrophic gastritis is related to the histological diagnosis of intestinal metaplasia and $\mathrm{Cdx} 2$ expression. Dig Dis Sci 2011;56:1119-26. 